\section{Great Ape Conservation Fund}

The Division of International Conservation of the US Fish and Wildlife Service invites submission of grant proposals for the conservation of apes (gorillas Gorilla gorilla, chimpanzees Pan troglodytes, bonobos Pan paniscus, orang-utans Pongo pygmaeus, and gibbons Hylobates spp.) throughout their ranges. The Great Ape Conservation Fund supports projects that develop local capacity to manage, conserve, research, or protect apes through the provision of funding, training, equipment and technical support.

The US Congress enacted the Great Ape Conservation Act of 2000 (GACA) in response to the decline of ape populations in Africa and Asia, which are now at a point that their long-term survival in the wild is in serious jeopardy. The Act has two purposes:

- to sustain viable populations of apes in the wild;

- to assist in the conservation and protection of apes by supporting the conservation programmes of countries in which ape populations are located.

To accomplish these purposes the GACA created the Great Ape Conservation Fund (GACF) to support and provide financial resources to conservation programmes of countries within the range of apes and to projects of persons and organizations with expertise applicable to the conservation of apes.

The GACF assists the conservation of apes by supporting:

- implementation of conservation programmes to protect ape populations at risk and their habitats;

- in situ research on ape populations and habitats, including surveys and monitoring;

- community outreach and conservation education;

- compliance with CITES and other applicable laws that prohibit or regulate the taking or trade of apes or regulate the use and management of ape habitat;

- protected area/reserve management in important ape ranges;

- development and execution of ape conservation management plans;

- efforts to decrease human-ape conflict;

- strengthening of local capacity to implement conservation programmes.

Proposals may be submitted by any wildlife management authority of a country within ape ranges, the
CITES Secretariat, or any individual or organization with relevant conservation experience. Proposals must be submitted in English (with the exception noted below), have the support of local government(s), and have matching funds, or in-kind support (salaries, equipment, etc.) provided by the organization receiving the grant or other partners. Applicants from Francophone Africa have the option of submitting proposals in French. French versions may require additional processing time and must be accompanied by a copy, on diskette, in MS Word or Wordperfect.

One original and one unbound copy of the proposal should be accompanied by an introductory covering letter and a cover page form. Documentation must demonstrate the participation and/or endorsement of the local government(s).

Because of the limited funds available, preference will be given to proposals requesting $\$ 30,000$ or less, but higher amounts may be requested. Funding is usually for 1 year or less, but projects lasting more than 1 year may be proposed. Those requiring more than 1 year of funding may be required to compete on an annual basis through submission of additional proposals.

Each grant recipient is required to submit regular progress and accounting reports. A final report that evaluates the success of meeting goals and objectives is required within 3 months of the project's completion.

Proposals postmarked by 1 March 2001 will be included in the first review. Proposals may be submitted throughout the year, and those postmarked after 1 March 2001 will be reviewed during subsequent sessions. Reviews and processing may require up to 6 months. Applicants are advised to specify a particular starting date bearing in mind the necessary processing and administrative time.

Further information and application details can be obtained from The Great Ape Conservation Fund at Division of International Conservation, US Fish and Wildlife Service, 4401 N. Fairfax Drive, ARLSQ 730, Arlington, VA 22203 1622, USA. Tel.: +1 703358 1758; fax: +1 703358 2849; e-mail: dave_ferguson@fws.gov. Proposals should be submitted to Chief, Division of International Conservation at the above mailing address and fax; tel.: +1 7033581754 . 